\title{
Sex or food? Effects of starvation, size and diet on sexual cannibalism in the amphipod crustacean Gammarus zaddachi
}

\author{
Joseph Edward Ironside • Samuel Thomas Dalgleish • Sean Joseph Kelly • \\ William Payne
}

Received: 29 August 2018/Accepted: 21 November 2018/Published online: 27 November 2018

(C) The Author(s) 2018

\begin{abstract}
Cannibalism of females by males before, during or immediately following sex has been attributed to misidentification of females, rejection of females as mates and prioritisation of feeding over reproduction. In the gammarid amphipod Gammarus zaddachi, males demonstrate that they have identified a female and accepted her as a suitable mate by engaging in precopula pairing behaviour. However, a male may later decide to eat the female after pairing with her. Laboratory experiments were performed in which survival of females in precopula pairs of $G$. zaddachi was monitored after their male partners had been subjected to starvation, herbivorous diets or diets containing animal matter. These indicate that the female is less likely to survive when she is abnormally small relative to the male, when the male is at risk of death by starvation or when the male's diet has lacked animal content. Decisions by males to forgo reproductive opportunities in favour of cannibalism, even after engaging in costly mate-guarding behaviour, emphasise the importance of carnivory in the trophic ecology of Gammarus species.
\end{abstract}

Handling Editor: Télesphore Sime-Ngando.

J. E. Ironside $(\varangle) \cdot$ S. T. Dalgleish .

S. J. Kelly · W. Payne

IBERS, Aberystwyth University, Aberystwyth,

Ceredigion SY23 3DA, UK

e-mail: jei@aber.ac.uk
Keywords Gammarus - Amphipod - Cannibalism · Diet $\cdot$ Starvation $\cdot$ Size

\section{Introduction}

Cannibalism of females by males before, during or immediately following sexual interactions (reversed sexual cannibalism) occurs in several classes of crustacean, including amphipods (Dick 1995), decapods (Haddon 1995) and isopods (Tsai and Dai 2003). This behaviour is particularly common in species where males are larger than females (Prenter et al. 2006) and has been observed frequently in gammarid amphipods of the genus Gammarus (Dick 1995). Gammarus spp. are often locally dominant in freshwater ecosystems (MacNeil et al. 1997) and are ecologically important as detritivores, predators and prey for organisms at higher trophic levels, such as fish (Andersen et al. 1993). Cannibalism can play an important role in the ecology of Gammarus spp., with implications for population persistence in the face of food scarcity (Polis 1981), interspecific competition (Dick 2008; Dick et al. 1993), parasite transmission (Bunke et al. 2015) and life history evolution (Hunte and Myers 1984). Hypotheses for the occurrence of reverse sexual cannibalism include misidentification of females by males (Gould 1984), rejection of nonpreferred females as mates by males (Arnqvist 1992; Stentenská and Pekár 2013) and prioritisation of 
feeding over reproduction by males when faced with food scarcity (Blamires 2011).

In Gammarus spp., females are receptive to insemination for only a brief period after moulting (Jormalainen 1998). Upon locating a pre-moult female, a male grasps her with his gnathopods and carries her beneath his ventral surface, forming a precopula pair (Hynes 1954). A male may carry a female in this way for several days, potentially incurring a considerable metabolic burden (Plaistow et al. 2003), although energy savings for both male and female partners may also be gained through formation of precopula pairs under conditions of starvation (Iltis et al. 2017). Once the female has moulted, the male fertilises her eggs, which have been laid into her brood pouch (Hynes 1954). Given that the post-moult period in which females are receptive to insemination is precisely the time at which they are most vulnerable to cannibalism (Dick 1995; Dick and Platvoet 1996; MacNeil et al. 1997), a male guarding a recently moulted female must choose between inseminating the female and eating her.

Gammarus males typically engage in thorough assessment behaviour of potential mates before making a decision to commence guarding (Williams 2007). G. pulex males appear able to assess a female's stage in the moult cycle, preferentially pairing with pre-moult females, but it is unclear whether they can discriminate females in egg-depositing moults from those in growth moults (Cornet et al. 2012). Gammarus males show a preference for females that are more fecund and therefore larger (Elwood et al. 1987). This has been used to explain the size-assortative pairing observed in several Gammarus species, by positing that males are found paired with the largest female that they can successfully defend from other males (Bollache and Cezilly 2004a; Elwood et al. 1987) or the largest female that they can successfully carry (Adams and Greenwood 1983; Elwood and Dick 1990; Williams 2007). G. pulex males that are close to moulting do not guard females (Bollache and Cezilly 2004b), and simulations suggest that size-assortative pairing could also arise from a preference of males for females that are closer to moulting than they are (Galipaud et al. 2013), given that larger individuals tend to moult less frequently. While no effect of male:female size ratio on reverse sexual cannibalism was observed in G. pulex (Dick 1995), high levels of cannibalism were observed in Gammarus zaddachi when large males were presented with pre-moult females smaller than their preferred size (Williams 2007). However, there is evidence that Gammarus males avoid cannibalising females of their own species where other prey is available. Gammarus pulex males predate the congeneric species Gammarus deubeni celticus more frequently than they engage in cannibalism (Dick et al. 1993) and cannibalise newly moulted female G. pulex less frequently than other smaller conspecifics, such as juveniles (Dick 1995).

Hunger appears to play a role in the decision by males to cannibalise females. In general, there is an inverse relationship between the availability of food and incidences of cannibalism in aquatic arthropods (Fox 1975; Istock 1966; Johansson 1992; Polis 1981), with noted rises in cannibalism among aquatic insects in response to decreases in the availability of detrital food sources (Fahy 1972). In G. pulex, there is an increased incidence of cannibalism of newly moulted females by males as the males are starved for longer periods of time, with starved males attacking premoult females as well as newly moulted females (Dick 1995).

Other effects of diet upon reverse sexual cannibalism in Gammarus spp. do not appear to have been investigated previously. Although commonly classified as shredders (MacNeil et al. 1997), Gammarus spp. feed opportunistically upon a wide variety of living and dead animal materials, including carrion (Hynes 1954; Willoughby and Sutcliffe 1976), fish eggs (Brown and Diamond 1984) and aquatic invertebrates (Delong et al. 1993) including other gammarid amphipods (MacNeil and Dick 2014). Supplementation of herbivorous diets with animal material can increase survival, growth, maturation and/or fecundity in Gammarus spp. (Cruz-Rivera and Hay 2000; Delong et al. 1993; Vassallo and Steele 1980), indicating that facultative carnivory has the potential to confer substantial fitness benefits.

In this study, the estuarine gammarid G. zaddachi is used to examine the effects of male:female size difference, starvation and diet upon reverse sexual cannibalism. The experiments focus on cannibalism of females by males after mate guarding has commenced, eliminating misidentification of females and rejection of females as potential mates as factors leading to cannibalism. Hence, the study focusses on factors which may cause to male to decide to prioritise 
nutrition over reproduction, even after investing considerable energy in guarding a female.

\section{Methods}

Collection and maintenance

Precopula pairs of G. zaddachi were collected from the mouth of the River Rheidol in Aberystwyth, Wales, UK $\left(52^{\circ} 24^{\prime} 40.8168^{\prime \prime} \mathrm{N},-4^{\circ} 5^{\prime} 13.6644^{\prime \prime} \mathrm{E}\right)$, at low tide. Dip nets (1 mm mesh size) were used to collect $G$. zaddachi from underneath rocks within the river. These were separated into containers of $100 \mathrm{ml}$ of river water from the collection site. In the laboratory, pairs were separated and each individual was placed in a transparent plastic container of $100 \mathrm{ml}$ of water from the collection site at $4{ }^{\circ} \mathrm{C}$ with a $1-\mathrm{cm}^{2}$ piece of rotted oak leaf as a food source (Bloor 2010). Each day, the water was replaced with new filtered river water, taken from the sample site at low tide, preventing the $G$. zaddachi from feeding on their own faeces or on any algae or microbial biofilms accumulating in the storage containers (Bloor 2010, 2011).

Experiment 1: Impact of size difference between male and female on reverse sexual cannibalism

A total of $101 G$. zaddachi precopula pairs were separated, and both members were blotted dry and weighed using an analytical balance to give their mass in grams. A linear regression of female weight on male weight was performed to test for size-assortative pair formation. Following a 24-h acclimatisation period, the pairs were reunited and each pair that had resumed precopula mate guarding was checked for survival every $24 \mathrm{~h}$ for a period of 17 days, during which they received no food. Where a female moulted successfully, had eggs in the brood pouch and was no longer being actively guarded by the male, she was judged to have reproduced successfully and was removed from the experiment.

At the end of the 17-day starvation period, pairs in which the female had not yet moulted were discarded from the analysis. The remaining, moulted females were categorised as surviving or non-surviving. In order to test for differences in the relative weights of males and females between pairs in which the female survived and pairs in which she did not survive, a univariate General Linear Model (GLM) was implemented in SPSS, with female weight as a dependent variable, survival as a fixed factor and male weight as a covariate. Separate linear regressions of female weight on male weight were performed for pairs in which the female survived and pairs in which the female died.

Experiment 2: Impact of starvation period on male survival and weight

A total of 40 male $G$. zaddachi were maintained for a standardising period of 7 days on a diet of $1-\mathrm{cm}^{2}$ rotted oak leaf. Food was then withdrawn, and the males were maintained for a starvation period of 3 weeks. Each male was blotted dry and weighed at the end of the standardisation period and at intervals of 2-3 days during the starvation period. A paired $t$ test between weights at Day 0 and weights at Day 21 was used to test whether the weight of males that survived the 21 days of starvation decreased significantly during this period.

Experiment 3: Impact of starvation period on reverse sexual cannibalism

A total of 120 G. zaddachi precopula pairs were separated, and the males were put into new containers for a standardising period of 7 days on a diet of $1-\mathrm{cm}^{2}$ rotted oak leaf. Food was then withdrawn, and the males were maintained for a further starvation period of $0,1,2$ or 3 weeks (30 males in each treatment). Following the starvation period, additional pairs of $G$. zaddachi were collected from the field and separated. The females from these new pairs were placed within the containers of the starved males and checked for survival after a period of $24 \mathrm{~h}$. Where a female moulted successfully, had eggs in the brood pouch and was no longer being actively guarded by the male, she was judged to have reproduced successfully and was removed from the experiment.

At the end of this period, pairs in which the male died before the female moulted or in which the female had not yet moulted were discarded from the analysis. The remaining females were categorised as surviving or non-surviving, and the data were placed in a $4 \times 2$ contingency table. Due to expected values of less than 5 , the table was analysed using a Fisher exact test of 
the hypothesis that survival of females differed between the four different starvation treatments.

Experiment 4: Impact of diet on reverse sexual cannibalism

A total of 80 male G. zaddachi were maintained on a standardised diet consisting of an excess of the green alga Ulva enteromorpha and freeze-dried chironomid larvae for 3 days. Each male was then randomly assigned to one of the four diets (20 individuals in each treatment group). The four diets were: (1) Ulva enteromorpha and chironomid larvae, (2) chironomid larvae only, (3) Ulva enteromorpha only and (4) no food. After the males had been maintained on these diets for 7 days, additional pairs of G. zaddachi were collected from the field and separated. The new females were placed within the containers of the starved males and checked for survival every $24 \mathrm{~h}$ for a period of 7 days. At the end of this period, females that had been taken by males into precopula pairs were categorised as surviving or non-surviving and the data were placed in a $4 \times 2$ contingency table. Due to expected values of less than 5, the table was analysed using a Fisher exact test of the hypothesis that cannibalism differed between the four different diet treatments.

\section{Results}

Experiment 1: Impact of size difference between male and female on reverse sexual cannibalism

A univariate General Linear Model (GLM) with female weight as a dependent variable, survival as a fixed factor and male weight as a covariate indicates that male weight was a significant predictor of female weight ( $F=11.499, p<0.0001$ ) (Fig. 3) but that there was no significant relation between female survival and female weight ( $F=1.907$, N.S.). Linear regression indicated that male weight was a significant predictor of female weight in those cases where the female survived, explaining $21 \%$ of variation in female weight $(y=0.298 x+8.512, \quad R=0.481$, $R^{2}=0.231, \quad$ adjusted $\left.R^{2}=0.211, \quad p<0.002\right)$ (Fig. 1). However, in cases where the female did not survive, male weight was not a significant predictor of

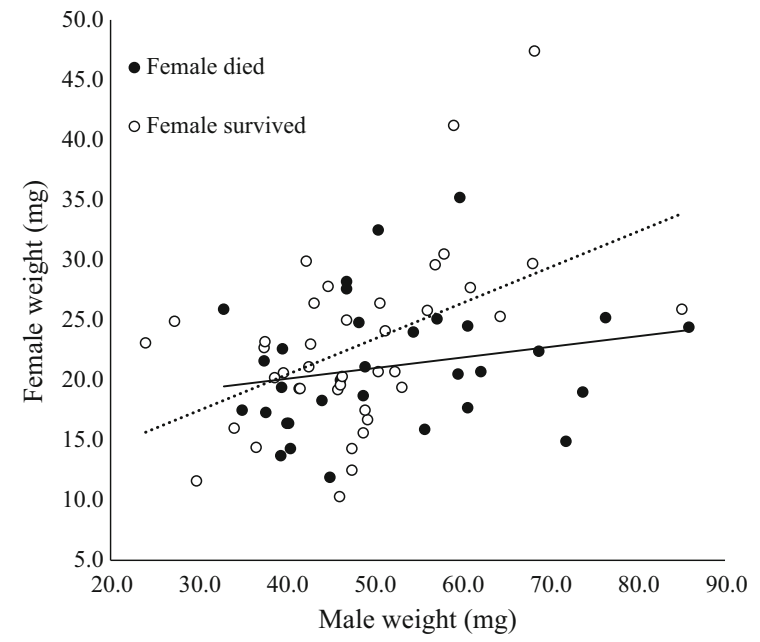

Fig. 1 Scatter plot of female weight against male weight in precopular pairs of Gammarus zaddachi

female weight $(y=0.089 x+16.570, R=0.222$, $R^{2}=0.049$, adjusted $R^{2}=0.019$, N.S.). Furthermore, survival of females appeared low where the size difference between the male and female was extreme. Out of nine cases in which the difference in weight between male and female exceeded $39.5 \mathrm{mg}$ (mean + 1 standard deviation), only one female survived.

Experiment 2: Impact of starvation period on male survival and weight

In total, 30/40 male Gammarus zaddachi survived the period of 21-day starvation. The survivors weighed significantly less after 21 days of starvation than at the beginning of the experiment $(t=8.392, d f=29$, $p<0.0001$ ) with most weight loss occurring between Day 3 and Day 14 (Fig. 2).

Experiment 3: Impact of starvation period on reverse sexual cannibalism

Survival of male $G$. zaddachi differed significantly between starvation periods of $0,7,14$ and 21 days $\left(\chi^{2}=17.9, d f=3, p<0.0001\right)$, decreasing as the period of starvation increased (Fig. 3). A Fisher exact test also indicated significant differences in the survival of moulted females when the males with which they were paired were starved for periods of 0 , 1,2 or 3 weeks $(p<0.0001)$. No females survived when paired with males that had been starved for 


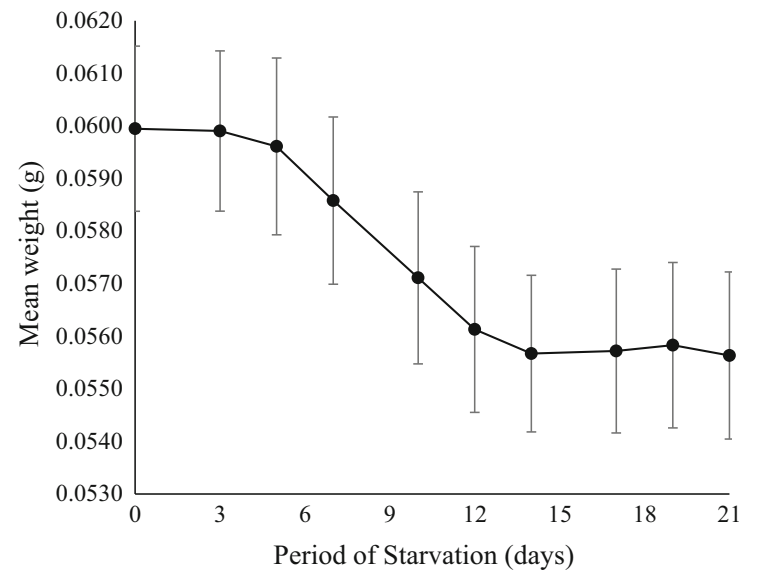

Fig. 2 Change in mean blotted dry weight of male Gammarus zaddachi over a period of 21-day starvation. Error bars indicate standard error of the mean

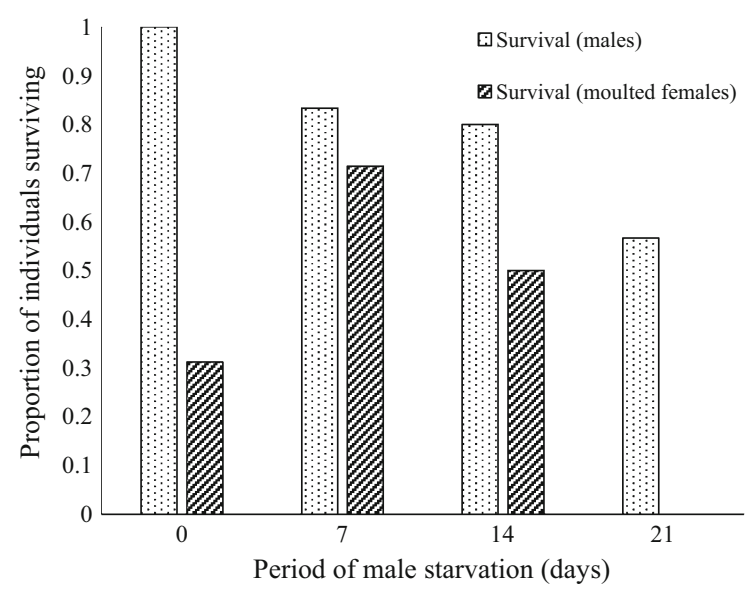

Fig. 3 Survival of males and moulted females in precopula pairs in which males had been starved for periods of $0,7,14$ or 21 days

21 days, except in cases where the male died before the female (Fig. 2). The proportion of moulted females surviving in pairs where males had not been starved was lower than the proportion in treatments where males had been starved for 7 or 14 days (Fisher exact $p=0.02$ ).

Experiment 4: Impact of diet on reverse sexual cannibalism

There was a significant difference in the proportion of females surviving when paired with males which had experienced different diets (Fisher exact $p<0.00001)$. Specifically, where the diets of males included chironomid larvae (diets 1 and 2), all females survived (Fig. 4). In contrast, where males were starved (diet 4) or fed only green algae (diet 3), some females died and were eaten, with twice as many incidences of cannibalism under conditions of complete starvation as when green algae were provided.

\section{Discussion}

In precopula pairs of $G$. zaddachi formed under natural conditions, Experiment 1 demonstrated a significant positive correlation between male weight and female weight in pairs where the female survived moulting to reproduce. No similar correlation was observed in pairs where the female was cannibalised before or shortly after moulting, suggesting that males may be more likely to cannibalise females of suboptimal size, even after pairing with them. This conclusion is reinforced by the observation that in 8/9 pairs in which the size difference between male and female was extreme $(>39.5 \mathrm{mg})$, the female was eaten. No similar impact of size difference between males and females upon reverse sexual cannibalism was demonstrated in precopula pairs of G. pulex formed under natural conditions (Dick 1995). However, high rates of cannibalism were observed when male G. zaddachi were presented with females smaller than they would normally pair with (Williams 2007). Together with the results of Experiment 1, these findings suggest that, in G. zaddachi at least, a male's decision whether to mate

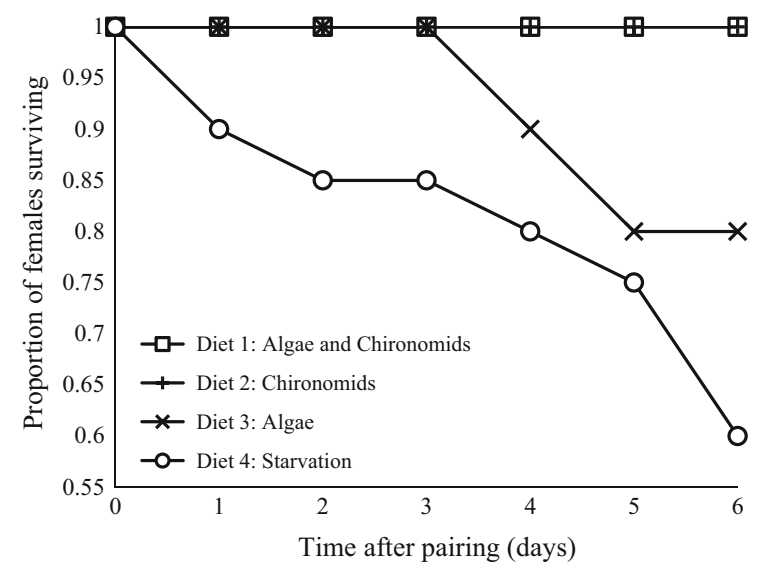

Fig. 4 Survival of female G. zaddachi when paired with males that had experienced different diets 
with a female or eat her is influenced by the size of the female relative to his own size. It may also be influenced by the higher likelihood that small females are undergoing a growth moult rather than a reproductive moult (Galipaud et al. 2013), rendering them unreceptive to males even when they have moulted.

Previously, a higher incidence of cannibalism of $G$. pulex females by males was demonstrated when the males were starved for 7 or 14 days in comparison with males which had not been starved (Dick 1995). In this case, males had been taken immediately from their natural environment prior to starvation. In contrast, the non-starved G. zaddachi males used in Experiment 3 were maintained on a diet of rotted oak leaves for 7 days prior to the experiment. Although G. zaddachi males can survive for several months on a diet of rotted leaves, this low-quality herbivorous diet may explain the relatively high proportion of females cannibalised by males in the non-starved treatment. A substantial change in behaviour occurred in males which had been starved for 21 days, with all males cannibalising their females. This corresponded with a decrease in the proportion of males surviving to $57 \%$, indicating that the surviving males were approaching lethal levels of food deprivation. This period of starvation also corresponded to a plateau in male weight loss with starvation, observed in Experiment 2, suggesting that males had exhausted their metabolic reserves. The results of these experiments confirm that when males are subject to extreme levels of starvation, they are more likely to decide to eat pre-moult females rather than mating with them. However, Experiment 3 also indicates that high levels of reverse sexual cannibalism can occur when males are maintained on a typical "shredder's" diet of course particulate organic matter (rotted oak leaves).

To the author's knowledge, this study is the first to demonstrate an impact of diet composition upon reverse sexual cannibalism in a gammarid amphipod. In Experiment 4, cannibalism of females by males occurred in cases where males were starved or fed an entirely herbivorous diet but did not occur in treatments where the males' diet included chironomid larvae. Previous studies have indicated that diets of green algae or chironomid larvae result in faster growth and earlier maturation in Gammarus spp. than diets of rotted leaves (Delong et al. 1993). The results of Experiment 4 demonstrate that the inclusion of animal matter in the diet of males inhibits reverse sexual cannibalistic behaviour to a greater extent than green algae alone. This suggests that animal prey is of sufficient importance in the diet of the male $G$. zaddachi that they will forgo reproductive opportunities in order to obtain it. This adds to the growing body of evidence that Gammarus spp. are not merely shredders but also important predators within freshwater ecosystems (MacNeil et al. 1997).

In conclusion, the results of these four experiments indicate that, even where a male $G$. zaddachi has accurately identified a pre-moult female and accepted her as a suitable mate (indicated by precopula pairing behaviour), he may later decide to eat her. This decision is more likely to be taken if the female is suboptimal in size, the male is at risk of death from starvation or the male's diet has been lacking in animal content. Decisions by males kept on herbivorous diets to forgo reproductive opportunities in favour of cannibalism, even after engaging in costly mateguarding behaviour, emphasise the importance of carnivory in the trophic ecology of Gammarus species.

Open Access This article is distributed under the terms of the Creative Commons Attribution 4.0 International License (http:// creativecommons.org/licenses/by/4.0/), which permits unrestricted use, distribution, and reproduction in any medium, provided you give appropriate credit to the original author(s) and the source, provide a link to the Creative Commons license, and indicate if changes were made.

\section{References}

Adams J, Greenwood PJ (1983) Why are males bigger than females in precopula pairs of Gammarus pulex? Behav Ecol Sociobiol 13:239-241. https://doi.org/10.1007/ bf00299670

Andersen TH, Friberg N, Hansen HO, Iversen TM, Jacobsen D, Krojgaard L (1993) The effects of introduction of brown trout (Salmo trutta L.) on Gammarus pulex L. drift and density in two fishless Danish streams. Arch Fur Hydrobiol 126:361-371

Arnqvist G (1992) Courtship behavior and sexual cannibalism in the semi-aquatic fishing spider, Dolomedes fimbriatus (Clerck) (Araneae: Pisauridae). J Arachnol 20:222-226

Blamires SJ (2011) Nutritional implications for sexual cannibalism in a sexually dimorphic orb web spider. Austral Ecol 36:389-394. https://doi.org/10.1111/j.1442-9993. 2010.02161.x

Bloor MC (2010) Animal standardisation for mixed species ecotoxicological studies: establishing a laboratory breeding programme for Gammarus pulex and Asellus aquaticus. Zool Baetica 21:179-190 
Bloor MC (2011) Dietary preference of Gammarus pulex and Asellus aquaticus during a laboratory breeding programme for ecotoxicological studies. Int J Zool. https://doi.org/10. $1155 / 2011 / 294394$

Bollache L, Cezilly F (2004a) Sexual selection on male body size and assortative pairing in Gammarus pulex (Crustacea: Amphipoda): field surveys and laboratory experiments. J Zool 264:135-141. https://doi.org/10.1017/s0952836904005643

Bollache L, Cezilly F (2004b) State-dependent pairing behaviour in male Gammarus pulex (L.) (Crustacea, Amphipoda): effects of time left to moult and prior pairing status. Behav Process 66:131-137. https://doi.org/10.1016/j. beproc.2004.01.010

Brown AF, Diamond M (1984) The consumption of rainbow trout (Salmo gairdneri Richardson) eggs by macroinvertebrates in the field. Freshw Biol 14:211-215. https://doi. org/10.1111/j.1365-2427.1984.tb00036.x

Bunke M, Alexander ME, Dick JTA, Hatcher MJ, Paterson R, Dunn $\operatorname{AM}(2015)$ Eaten alive: cannibalism is enhanced by parasites. R Soc Open Sci. https://doi.org/10.1098/rsos.140369

Cornet S, Luquet G, Bollache L (2012) Influence of female moulting status on pairing decisions and size-assortative mating in amphipods. J Zool 286:312-319. https://doi.org/ 10.1111/j.1469-7998.2011.00882.x

Cruz-Rivera E, Hay ME (2000) The effects of diet mixing on consumer fitness: macroalgae, epiphytes, and animal matter as food for marine amphipods. Oecologia 123:252-264. https://doi.org/10.1007/s004420051012

Delong MD, Summers RB, Thorp JH (1993) Influence of food type on the growth of a riverine amphipod, Gammarus fasciatus. Can J Fish Aquat Sci 50:1891-1896. https://doi. org/10.1139/f93-211

Dick JTA (1995) The cannibalistic behaviour of two Gammarus species (Crustacea: Amphipoda). J Zool 236:697-706

Dick JTA (2008) Role of behaviour in biological invasions and species distributions; lessons from interactions between the invasive Gammarus pulex and the native G. duebeni (Crustacea: Amphipoda). Contrib Zool 77:91-98

Dick JTA, Platvoet D (1996) Intraguild predation and species exclusions in amphipods: the interaction of behaviour, physiology and environment. Freshw Biol 36:375-383. https://doi.org/10.1046/j.1365-2427.1996.00106.x

Dick JTA, Montgomery WI, Elwood RW (1993) Replacement of the indigenous amphipod Gammarus deubeni celticus by the introduced Gammarus pulex: differential cannibalism and mutual predation. J Anim Ecol 62:79-88

Elwood RW, Dick JTA (1990) The amorous Gammarus: the. relationship between precopula duration and size assortative mating in G. pulex. Anim Behav 39:828-833. https:// doi.org/10.1016/s0003-3472(05)80946-7

Elwood R, Gibson J, Neil S (1987) The amorous Gammarus: size assortative mating in G. pulex. Anim Behav 35:1-6. https://doi.org/10.1016/s0003-3472(87)80203-8

Fahy E (1972) The feeding behaviour of some common lotic insect species in two streams of differing detrital content. J Zool 167:337-350

Fox LR (1975) Factors influencing cannibalism, a mechanism of population limitation in the predator Notonecta hoffmanni. Ecology 56:933-941

Galipaud M, Bollache L, Dechaume-Moncharmont FX (2013) Assortative mating by size without a size-based preference: the female-sooner norm as a mate-guarding criterion. Anim Behav 85:35-41. https://doi.org/10.1016/j.anbehav.2012. 09.038

Gould SJ (1984) Only his wings remained. Nat Hist 93:10-18

Haddon M (1995) Avoidance of post-coital cannibalism in the brachyurid paddle crab Ovalipes catharus. Oecologia 104:256-258

Hunte W, Myers RA (1984) Phototaxis and cannibalism in gammaridean amphipods. Mar Biol 81:75-79. https://doi. org/10.1007/bf00397628

Hynes HBN (1954) The ecology of Gammarus deubeni Lillejeborg and its occurrence in freshwater in western Britain. J Anim Ecol 23:38-84

Iltis C, Dechaume-Moncharmont FX, Galipaud M, Moreau J, Bollache L, Louapre P (2017) The curse of being single: both male and female Gammarus pulex benefit energetically from precopulatory mate guarding. Anim Behav 130:67-72. https://doi.org/10.1016/j.anbehav.2017.06.013

Istock CA (1966) Distribution, coexistence and competition of whirligig beetles. Evolution 20:211-234. https://doi.org/ $10.2307 / 2406575$

Johansson F (1992) Effects of zooplankton availability and foraging mode on cannibalism in three dragonfly larvae. Oecologia 91:179-183

Jormalainen V (1998) Precopulatory mate guarding in crustaceans: male competitive strategy and intersexual conflict. Q Rev Biol 73:275-304. https://doi.org/10.1086/420306

MacNeil C, Dick JTA (2014) The enemy of my enemy is my friend: intraguild predation between invaders and natives facilitates coexistence with shared invasive prey. Biol Lett 10:4. https://doi.org/10.1098/rsbl.2014.0398

MacNeil C, Dick JT, Elwood RW (1997) The trophic ecology of freshwater Gammarus spp. (Crustacea: Amphipoda): Problems and perspectives concerning the functional feeding group concept. Biol Rev Camb Philos Soc 72:349-364. https://doi.org/10.1017/s0006323196005038

Plaistow SJ, Bollache L, Cezilly F (2003) Energetically costly precopulatory mate guarding in the amphipod Gammarus pulex: causes and consequences. Anim Behav 65:683-691. https://doi.org/10.1006/anbe.2003.2116

Polis GA (1981) The evolution and dynamics of intraspecific predation. Annu Rev Ecol Syst 12:225-251. https://doi. org/10.1146/annurev.es.12.110181.001301

Prenter J, MacNeil C, Elwood RW (2006) Sexual cannibalism and mate choice. Anim Behav 71:481-490. https://doi.org/ 10.1016/j.anbehav.2005.05.011

Tsai ML, Dai CF (2003) Cannibalism within mating pairs of the parasitic isopod, Ichthyoxenus fushanensis. J Crustacean Biol 23:662-668. https://doi.org/10.1651/c-2343

Vassallo L, Steele DH (1980) Survival and growth of young Gammarus lawrencianus Bousfield, 1956, on different diets. Crustac Suppl 6:118-125

Williams DD (2007) Size-assortative pairing in the lotic amphipod Gammarus zaddachi, an examination of hypotheses and the influence of current speed. Aquat Ecol 41:309-317. https://doi.org/10.1007/s10452-006-9075-x

Willoughby LG, Sutcliffe DW (1976) Experiments on feeding and growth of the amphipod Gammarus pulex (L.) related to its distribution in the River Duddon. Freshw Biol 6:577-586 